\title{
НАЦИОНАЛЬНЫЙ СУВЕРЕНИТЕТ В ПОЛИТИЧЕСКОЙ КУЛЬТУРЕ ФРАНЦИИ
}

Аннотация. В статье рассматриваются исторические аспекты понятия суверенитета в контексте особенностей формирования франиузской государственности, нации и её политической культуры. Процессы евроинтеграции, развернувшиеся в послевоенный период и в особенности в последние десятилетия, привели к передаче всё больших традиционных полномочий национального государства на наднациональный уровень и заметному пересмотру классических представлений о суверенитете.

Ключевые слова: Франщия, суверенитет, государство, Пятая республика, европейская интеграция.

Проблема национального суверенитета во Франции, которая является исторической колыбелью самого́ этого понятия, стала ныне одним из важнейших объектов социально-политической борьбы, от исхода которой во многом зависят его судьбы и в международном, прежде всего европейском масштабе.

Французский энциклопедический словарь «Лярусс» определяет суверенитет как «признание за государством высшей власти, предполагающей его исключительную правомочность в пределах национальной территории (внутренний суверенитет) и абсолютную независимость в международном плане, где она ограничена только его собственными обязательствами (внешний суверенитет)»1.

Столь однозначная формулировка, не допускающая, казалось бы, каких-либо иных толкований, связана с особенностями формирования французской государственности, нации и её политической культуры.

У многих европейских народов (немцев или итальянцев) создание единого государства происходило сравнительно поздно - во второй половине XIX, а в Центральной и Восточной Европе даже XX в., когда процесс становления общей национальной культуры зашёл уже достаточно далеко. Напротив, во Франции формирование такого государства началось гораздо раньше, причём именно оно стало основным инструментом формирования национальной идентичности на весьма неоднородной этнокультурной основе.

Исходным рубежом этого процесса стало завоевание предшественницы Франции Трансальпийской Галлии легионами Римской империи в I в. н.э. На протяжении пяти столетий господства Рима она навязала пёстрому конгломерату конфликтующих между собой кельтских племён свою модель централизованной военно-гражданской администрации, писаное право, язык, а затем и общую религию - христианство. Именно эта модель стала матрицей французской государственности.

После падения Рима этот процесс получил дальнейшее продолжение, когда к кельтской

(C) Рубинский Юрий Ильич - доктор исторических наук, профессор, главный научный сотрудник, руководитель Центра французских исследований ИЕ РАН. Адрес: 125009, Россия, Москва, ул. Моховая, д. 11, стр. 3. E-mail: yuri.rubinski@mail.ru.

DOI: http://dx.doi.org/10.15211/vestnikieran12019610

${ }^{1}$ Grand Larousse en 5 volumes. T. 5, Librairie Larousse, 1989. P. 2872. 
основе будущей нации добавились германские племена. Сильнейшее из них - франки создали общее государство в его естественных границах, дав ему первые династии королей и само́ название. За ними последовали норманны, осевшие на севере страны.

Необходимость их сплочения, которое исключало бы сепаратистские тенденции разных регионов, поощряемые соседями «извне», объясняет сравнительно раннее преодоление страной феодальной раздробленности: именно во Франции впервые в Европе сложилась абсолютная монархия, апогеем которой стал пышный двор «короля - Солнца» Людовика XIV в Bepсале. Её глава превратился из «сюзерена», т.е. вершины пирамиды полунезависимых, зачастую мятежных вассалов в «суверена» - высшую, конечную инстанцию единой административной, судебной, финансовой, военной власти.

К той же эпохе относится и происхождение термина «королевские прерогативы» («les fonctions régaliennes»), в которые входят обеспечение безопасности страны и граждан, внешняя политика, оборона. Они неизменно закрепляются за носителем суверенной верховной власти при всех многочисленных режимах, сменявшихся во Франции на протяжении более двух столетий после революции 1789 г. - конституционной монархии, двух империй и пяти республик - как парламентских, так и президентских.

Конституция нынешней, полупрезидентской Пятой республики, созданной в 1958 г. генералом де Голлем, гласит: «Национальный суверенитет принадлежит народу, который осуществляет его через своих представителей и путём референдума. Никакая часть народа или личность не может присвоить себе его осуществление» ${ }^{\text {. }}$.

На практике это означает, что избранный всеобщим голосованием президент решает все вопросы, относящиеся к «королевским прерогативам» напрямую с соответствующими министрами-исполнителями, зачастую помимо назначенного им же премьер-министра, правительства и парламентского большинства.

К той же исторической эпохе - XVI-XVII вв. относится и становление во Франции внешнего аспекта её суверенитета, понятие которого впервые сформулировал выдающийся французский юрист Жан Боден (1576 г.): «Суверенитет является абсолютной и постоянной властью республики, которая не ограничивается ни компетенцией, ни временем».

Конкретной реализацией этого принципа стала Вестфальская система, которая подвела итоги Тридцатилетней войны (1618-1648 гг.). Опустошённая, обескровленная религиозными и династическими войнами Европа искала тогда общепризнанный принцип сосуществования суверенных государств, которым стало взаимное признание права каждого из них определять свои формы правления и конфессию самостоятельно, без вмешательства извне в его внутренние дела. Несмотря на то, что на практике этот принцип постоянно нарушался, он остаётся юридической основой правил функционирования всех международных организаций вплоть до наших дней, начиная с главной из них - ООН с её Уставом, где Франция занимает ключевой пост одного из пяти постоянных членов Совета Безопасности с правом вето.

Вместе с тем её отношение к проблеме суверенитета было всегда отмечено двойственностью, противоречивостью.

Её внутреннее измерение оказывается уязвимым ввиду ощутимых смысловых различий между понятиями национального и народного суверенитета, которые фигурируют в действующей Конституции Пятой республики.

Первое относится в равной мере ко всем гражданам без исключения, которые считаются французами вне зависимости от их этнического происхождения, социального положения, религии, политических убеждений: не случайно поэтому термины «национальность» и «граж-

\footnotetext{
${ }^{1}$ Titre premier - De la Souveraineté, Article 3. Constitution de la République française. Dalloz, Paris, 2010. P. 19.
} Научно-аналитический вестник ИЕ РАН, 2019, №1 
данство» чаще всего обозначаются нередко одним словом (la nationalité).

В то же время народный суверенитет ограничивается разделением и равновесием властей, баланс которых в Пятой республике изначально склоняется в ущерб законодательной, и демократическим принципам победы большинства голосов избирателей на выборах всех уровней. Хотя при этом права меньшинств гарантируются гражданскими свободами, их влияние на решения, которые принимаются суверенной верховной властью в рамках «королевских прерогатив», неизбежно ограничивается.

Другим объективным ограничителем национального государственного суверенитета как внутреннего, так и внешнего являются глобализация и европейская интеграция, в которых Франция активно участвует. Под влиянием мощных трансграничных потоков товаров, капиталов, людей полномочия центральных правительств отдельных государств постепенно переходят либо вниз, в пользу выборных органов самоуправления регионов или муниципалитетов, либо вверх - к общим институтам интегрированных международных организаций, прежде всего Евросоюза, где немалая часть принятых решений и правовых норм имеет преимущество перед национальным законодательством.

Заметно растёт и международная роль негосударственных акторов - транснациональных корпораций (ТНК), организаций гражданского общества (НПО) - экологических, правозащитных, религиозных, культурных, сетей международной преступности и терроризма.

Хотя Франция с её традициями жёсткой административной централизации «единого и неделимого» национального государства, восходящими к абсолютной монархии, якобинской диктатуре и наполеоновской империи, упорно сопротивлялась этим тенденциям, она никак не может полностью игнорировать их. Тем более что идеи объединения европейских государств путём ограничения их суверенитета во имя высоких принципов мира, демократических свобод, совместного сопротивления угрозам извне также имеют в её истории глубокие корни.

Авторство первого из них также принадлежит французу - герцогу де Сюлли (министру-сюринтенданту) короля Генриха IV (конец XVI - начало XVII вв.) - современнику его антипода, родоначальника идеи государственного суверенитета Жана Бодена. Следующими вехами на том же пути стали идеи аббата Сен-Пьера (1712 г.), великого писателя В. Гюго, выдвинувшего проект «Соединённых Штатов Европы» по образцу и в союзе с США в Северной Америке (1849 г.), план Европейской федерации министра Третьей республики А. Бриана (1928 г.) и т.д.

Отправной точкой в практической реализации всех этих идей послужила речь министра иностранных дел Четвёртой республики Р. Шумана 9 мая 1950 г. - в пятую годовщину после окончания Второй мировой войны. Он предложил объединить производство и сбыт угля и стали Франции и Германии под контролем общих наднациональных институтов с тем, чтобы сделать в будущем новую войну между ними не только беспредметной, но и «материально невозможной».

Формирование после этого Европейского объединения угля и стали (ЕОУС) Францией, ФРГ, Италией, Бельгией, Голландией и Люксембургом стало началом процесса европейского строительства, который прошёл с тех пор долгий путь вплоть до современного Евросоюза.

При этом международные факторы, которые способствовали развитию этого процесса холодная война, расколовшая мир и Европу на две противостоящие системы и военные блоки, как и распад колониальной системы европейских держав во многом определяли расстановку партийно-политических сил в самой Франции.

Идею «европеизма» - ограничения национального суверенитета стран Западной Европы во имя общих ценностей и противодействия внешним угрозам встретили решительное со- 
противление на крайних флангах партийно-политического спектра Четвёртой республики коммунистов слева и голлистов справа, за которых голосовали на выборах в общей сложности боле $40 \%$ всех избирателей.

Ответом «европеистов» стало создание т.н. «Третьей силы»- блока социалистов, католического Народно-республиканского движения (МРП) и радикалов, а затем также консервативных «независимых и крестьян», которые в тех или иных комбинациях оставались у власти вплоть до падения Четвёртой республики.

С учётом существенных расхождений традиционного идейного багажа этих партий по многим социально-экономическим и политическим проблемам связующим звеном между ними стал именно «европеизм». Не случайно в международном плане лидеры этих же политических течений - социал-демократов, либералов, христианских демократов, в частности, последних - Р. Шума́н, К. Аденауэр, А де Гаспери вошли в историю как «отцы-основатели» европейского строительства.

Причём в условиях холодной войны европеизм оказался неразрывно связанным с атлантизмом - поддержкой Североатлантического союза, созданного в 1949 г. по инициативе и под безраздельным лидерством США.

Вместе с тем во Франции эта связка не раз давала сбои. Наиболее значительным среди них стал провал 30 августа 1954 г. в нижней палате французского парламента - Национальном собрании проекта договора о создании «Европейского оборонительного сообщества» (EOC). Этот проект, автором которого являлся французский министр Р. Плевен, был призван легализировать перевооружение ФРГ, которого решительно требовали США от союзников по НАТО с началом войны в Корее.

Однако план создания «европейской армии», в рамках которой государства-участники утрачивали суверенный контроль над своими вооружёнными силами, встретил наиболее решительный отпор именно во Франции, где травма от поражения 1940 г., оккупации и традиции движения Сопротивления были ещё весьма чувствительными.

Немалую роль сыграла также вовлечённость страны в войну в Индокитае, начавшая процесс распада французской колониальной империи.

В таких условиях решительное осуждение «европейской армии» коммунистами и голлистами вызвало раскол правящего центристского блока, что привело к краху ЕОС, а вместе с ним и проекта создания «Европейского политического сообщества» (ЕПС) с наднациональными, федеративными полномочиями ${ }^{1}$.

Хотя под давлением США, пригрозивших Франции «мучительным пересмотром» союзнических отношений, перевооружение ФРГ было реализовано в 1955 г. иным путём - вступлением её в НАТО, этот эпизод наглядно продемонстрировал объективные пределы готовности Парижа отказаться от части своего национально-государственного суверенитета.

Несмотря на то, что за прошедшие с тех пор более 60 лет ситуация в Европе и в мире изменилась коренным образом, многие традиции в отношении Франции к проблемам национально-государственного суверенитета отчётливо дают себя знать вплоть до наших дней.

\footnotetext{
${ }^{1}$ La Querelle de la C.E.D.: essais d'analyse sociologique. Sous la direction de Raymond Aron et Daniel Lerner.
} Librairie Armand Colin, Paris, 1956. P. 210-215. 


\section{Список литературы/References}

Grand Larousse en 5 volumes. T. 5, Librairie Larousse, 1989. P. 2872.

Titre premier - De la Souveraineté, Article 3. Constitution de la République française. Dalloz, Paris, 2010. P. 19.

La Querelle de la C.E.D.: essais d'analyse sociologique. Sous la diréction de Raymond Aron et Daniel Lerner. Liberairie Armand Colin, Paris, 1956. P. 210-215.

\section{National sovereignty in the political culture of France}

Author. Yuriy Rubinskiy, Doctor of Sciences (History), Professor, Chief Research Associate, Head of Centre for Studies of France, Institute of Europe, Russian Academy of Sciences. Address: 11-3, Mokhovaya str., Moscow, Russia, 125009. E-mail: yuri.rubinski@mail.ru.

Abstract. The article discusses the historical aspects of the concept of sovereignty in the context of the peculiarities of the formation of French statehood, the nation and its political culture. The processes of European integration that unfolded in the post-war period and especially in recent decades, led to the transfer of the increasing traditional powers of the national state to a supranational level and a noticeable revision of the classical notions of sovereignty. tion.

Key words. France, sovereignty, state, Fifth Republic, European Union, European integra-

DOI: http://dx.doi.org/10.15211/vestnikieran12019610 